\title{
Application of desirability function for optimizing the performance characteristics of carbonitrided bushes
}

\author{
Boby John*
}

SQC \& OR Unit, Indian Statistical Institute, 8th Mile, Mysore Road, Bangalore, Karnataka State, 560 059, India

\section{H R O N I C L E}

\section{Article history:}

Received January 152012

Received in revised format

April 152013

Accepted April 152013

Available online

April 162013

Keywords:

Powder Metallurgy

Carbonitriding

Multiple Response Optimisation

Desirability Function

Design of Experiments

Analysis of Variance

\begin{abstract}
A B S T R A C T
The performance of a product is generally characterized by more than one response variable. Hence the management often faces the problem of simultaneous optimization of many response variables. This study was undertaken to simultaneously optimize the surface hardness and case depth of carbonitrided bushes. Even though lots of literature has been published on various methodologies for tackling the multi-response optimization problem, the simultaneous optimization of heat treated properties of carbonitrided bushes are not reported yet. In this research the effect of four factors and two interactions on surface hardness and case depth of carbontirded bushes were studied using design of experiments. Based on the experimental results, the expected values of the heat treated properties of the bushes were estimated for all possible combination of factors. Then the best combination which, simultaneously optimized the response variables, was arrived at using desirability function. The study showed that the optimum combination obtained through desirability function approach not only minimized the variation around the targets of surface hardness and case depth but also was superior to the ones obtained by optimizing the response variables separately. Moreover this study provides a useful and effective approach to design the production process to manufacture bushes with customer specified surface hardness and case depth targets.
\end{abstract}

\section{Introduction}

The powder metallurgy technique is relatively cost effective and simple way to produce bushes with good wear resistance and better mechanical properties. The carbonitriding has become the most popular process for surface hardening of bushes. In carbonitriding, ammonia is added to the furnace atmosphere of endo gas and hydrocarbon. The ammonia dissociates at the metallic surface and atomic nitrogen is formed, which will diffuse into the material along with carbon. The nitrogen not only increases the surface hardness but also stabilizes the austenilite and thus increases the hardenability of sintered steel (Boby, 2012).

The specifications on surface hardness and case depth would vary from customer to customer based on the application of bushes. Hence the knowledge on the effect of various process parameters on the

* Corresponding author. Tel: +91 8028483007 Fax: +91 (80) 28484265

E-mail: boby@isibang.ac.in; bobymon@outlook.com (B. John)

(C) 2013 Growing Science Ltd. All rights reserved. doi: $10.5267 /$ j.ijiec.2013.04.003 
surface hardness and case depth was essential to quickly change the process setting to manufacture bushes with different customer requirements. The challenge was to simultaneously minimize the variation around customer specified targets on surface hardness and case depth. The studies on simultaneous optimization of heat treated properties of carbonitrided bushes were not reported yet. Hence this research was undertaken.

The methodologies used were design of experiments and desirability function. The design of experiments (Dal Re 1999; Baragetti \& Terranova 2000; Surm et al., 2005; Wang et al., 2008; Bhuiyan et al, 2011; Boby, 2012, Murali Krishna et. al, 2013) was used to establish the relationship between the heat treated properties with carbonitriding process parameters. Then the best combination of significant process parameter values, which would simultaneously optimize surface hardness and case depth, were identified using desirability function.

The reminder of this paper is arranged as follows: in session 2, a brief description of various approaches for simultaneous optimisation problem is presented. The details of the desirability function approach are given in session 3. The experimentation and data analysis is shown in session 4 . In session 5 , the result obtained through the implementation of the solution is presented and the conclusions are given in session 6 .

\section{Simultaneous optimisation of response variables}

The performance of a product or service is generally characterized by many response variables. In many situations these response variables or quality characteristics are controlled by a set of independent factors. Often the best values of these control parameters, which would simultaneously optimise the response variables, need to be identified.

A common approach for multi response optimisation is to identify one of the response variables as primary response and optimise it subject to the condition that the other response variables satisfy the specified requirements. In other words the problem is formulated as constraint optimisation problem (linear or nonlinear programming problem) with primary response as objective function and other responses as constraints. One major drawback of this approach is that it will not result in simultaneous optimisation of all responses.

Recently, several approaches to multiple response optimisation have been proposed in literature. For the optimisation of duel responses, Montgomery and Castillo (1993) suggested a non-linear programming solution. Myers and Carter (1973) proposed response surface techniques. Harrington (1965) and Derringer (1994) developed the desirability function approach for simultaneous optimisation of multiple responses. Koksoy and Yalcinoz (2006) presented a methodology for analysing several quality characteristics simultaneously using the mean square error criterion. Su and Tong (1997) proposed multi - response robust design using principal component analysis. Hsu (2004) presented an integrated optimisation approach based on neural networks, exponential desirability functions \& tabu search.

Liao (2004) proposed data envelopment analysis ranking approach to optimise multi-response problems. Antony et al. (2006) used neuro-fuzzy model and Taguchi methodology to tackle multiple response optimisation problems. Saha and Mandal (2013) showed that the surface roughness, power consumption and frequency of vibration of turning process can be simultaneously optimized using gray relational analysis. Chakravorty et al (2013) published a comparative study on the effectiveness of various engineer friendly multi response optimization techniques for optimization of ultrasonic machining processes. Of all the aforementioned approaches, the utilization of desirability function is the most popular and strongly suggested method. This study used the desirability function approach to optimise the multiple responses of a carbonitriding process. 


\section{Desirability Function}

In the desirability function approach, each response is transformed into a desirability value $d$ and the total desirability function $\mathrm{D}$, which is the geometric mean of the individual desirability values, is computed and optimised. The desirability is defined such that if a response is beyond the acceptable limit, then the corresponding desirability value will be 0 . If the response is on target then the desirability value will be equal to 1 . When the response falls within the tolerance interval but not on the target, the corresponding desirability will lie between 0 and 1 . As the response approaches the target, the desirability value becomes closer and closer to 1 .

The class of desirability functions is divided into three types, namely Nominal the best (NTB), Smaller the better (STB) and Larger the better (LTB). For the NTB type, the desirability function is defined as

$$
d=\left\{\begin{array}{cc}
\left|\frac{y-L S L}{T-L S L}\right|^{\alpha} & \text { LSL }<\mathrm{y} \leq \mathrm{T} \\
\left|\frac{y-U S L}{T-U S L}\right|^{\beta} & \mathrm{T}<\mathrm{y}<\mathrm{USL} \\
0 & \mathrm{y} \quad \leq \mathrm{LSL} \text { or } \mathrm{y} \geq \text { USL }
\end{array}\right.
$$

where $L S L$, USL and $T$ are the lower specification limit, upper specification limit and target for the response $y$. The weights $\alpha$ and $\beta$ needs to be specified depending on the desirability of response variable $y$ with respect to $U S L, L S L$ and target.For the STB type, the desirability function is defined as

$$
d=\left\{\begin{array}{cc}
\left|\frac{y-U S L}{y_{\min }-U S L}\right|^{\alpha} & y_{\min }<y<U S L \\
0 & y \geq U S L \\
1 & y \leq y_{\min }
\end{array}\right.
$$

where USL is the upper specification limit, $\alpha$ is the weight and $y_{\min }$ is the most desirable minimum value, which can be practically achievable. For the LTB type, the desirability function is defined as

$$
d=\left\{\begin{array}{cc}
\left|\frac{y-L S L}{y_{\max }-L S L}\right|^{\alpha} & L S L<y<y_{\max } \\
0 & y \leq L S L \\
1 & y \geq y_{\max }
\end{array}\right.
$$

where $L S L$ is the lower specification limit, $\alpha$ is the weight and $y_{\max }$ is the most desirable maximum value, which can be practically achievable.After transforming each response variable $y_{i}$ to a corresponding desirability value $d_{i}$ using Eq. (1), Eq. (2) or Eq. (3), the total desirability function $D$ is computed as the geometric mean of these individual $d_{i}$ 's, $i=1,2,---, p$

$\mathrm{D}=\left(d_{1} \times d_{2} \times---\times d_{p}\right)^{1 / p}$

\section{Experimentation and Analysis}

The discussions with the technical personals of the company revealed that four parameters impacts the heat-treated properties of carbonitrided bushes. Accordingly an experiment was designed with soaking time (A), temperature (B), green density (C) and the material (D) as factors. It was decided to try out 
three levels for all the four factors in the experiment. The technical personals also suspected the interaction between soaking time \& temperature $(\mathrm{AxB})$ and the interaction between soaking time \& green density (AxC). The full factorial design would require 81 experiments, which was not economically feasible under the given situation. Hence the experiment was designed using $\mathrm{L}_{27}$ orthogonal array (Phadke, 1989). The factors with levels chosen for experimentation are given in Table 1. The surface hardness (in HRD) and case depth (in $\mathrm{mm}$ ) were taken as the responses. The responses with specified USL, LSL \& target values are given in the Table 2.

Table 1

Factors with levels

\begin{tabular}{clcccc}
\hline SL No. & Factor Name & Code & & \multicolumn{2}{c}{ Levels } \\
2 & Medium & High \\
\hline 1. & Soaking Time (Minutes) & A & Low & Medium & High \\
2. & Temperature $\left({ }^{\circ} \mathrm{C}\right)$ & B & Low & Medium & High \\
3. & Green Density $(\mathrm{gm} / \mathrm{cc})$ & $\mathrm{C}$ & Low & Medium & Type III \\
\hline
\end{tabular}

Table 2

Responses with Specification

\begin{tabular}{clccc}
\hline SL No & Response & LSL & USL & Target \\
\hline 1. & Surface Hardness & 420 & 580 & 500 \\
2. & Case Depth & 0.1 & 0.8 & 0.45 \\
\hline
\end{tabular}

The experiments were conducted as per the design. Each experiment was replicated twice. The experimental layout is given in Table 3.

Table 3

Experimental Layout with Response values

\begin{tabular}{|c|c|c|c|c|}
\hline Exp No. & Soaking Time & Temperature & Green Density & Material \\
\hline 1 & Low & Low & Low & Type I \\
\hline 2 & Low & Low & Medium & Type II \\
\hline 3 & Low & Low & High & Type III \\
\hline 4 & Low & Medium & Low & Type II \\
\hline 5 & Low & Medium & Medium & Type III \\
\hline 6 & Low & Medium & High & Type I \\
\hline 7 & Low & High & Low & Type III \\
\hline 8 & Low & High & Medium & Type I \\
\hline 9 & Low & High & High & Type II \\
\hline 10 & Medium & Low & Low & Type I \\
\hline 11 & Medium & Low & Medium & Type II \\
\hline 12 & Medium & Low & High & Type III \\
\hline 13 & Medium & Medium & Low & Type II \\
\hline 14 & Medium & Medium & Medium & Type III \\
\hline 15 & Medium & Medium & High & Type I \\
\hline 16 & Medium & High & Low & Type III \\
\hline 17 & Medium & High & Medium & Type I \\
\hline 18 & Medium & High & High & Type II \\
\hline 19 & High & Low & Low & Type I \\
\hline 20 & High & Low & Medium & Type II \\
\hline 21 & High & Low & High & Type III \\
\hline 22 & High & Medium & Low & Type II \\
\hline 23 & High & Medium & Medium & Type III \\
\hline 24 & High & Medium & High & Type I \\
\hline 25 & High & High & Low & Type III \\
\hline 26 & High & High & Medium & Type I \\
\hline 27 & High & High & High & Type II \\
\hline
\end{tabular}


The responses were individually subjected to analysis of variance (Montgomery, 2001) to identify the significant main effects and interactions. The ANOVA table for surface hardness is given in Table 4 and the corresponding residual plots is given in Fig. 1.

Table 4

ANOVA table for Surface Hardness

\begin{tabular}{lccccc}
\hline Source & DF & SS & MS & F & p \\
\hline Soaking Time & 2 & 1612 & 806 & 0.8 & 0.458 \\
Temperature & 2 & 3231 & 1616 & 1.6 & 0.216 \\
Green Density & 2 & 20083 & 10042 & 9.92 & 0.000 \\
Material & 2 & 30112 & 15056 & 14.9 & 0.000 \\
Soaking Time x Temperature & 4 & 12524 & 3131 & 3.09 & 0.027 \\
Soaking Time x Green Density & 4 & 806 & 202 & 0.2 & 0.937 \\
Error & 37 & 37436 & 1012 & & \\
\hline Total & 53 & 105805 & & & \\
\hline
\end{tabular}

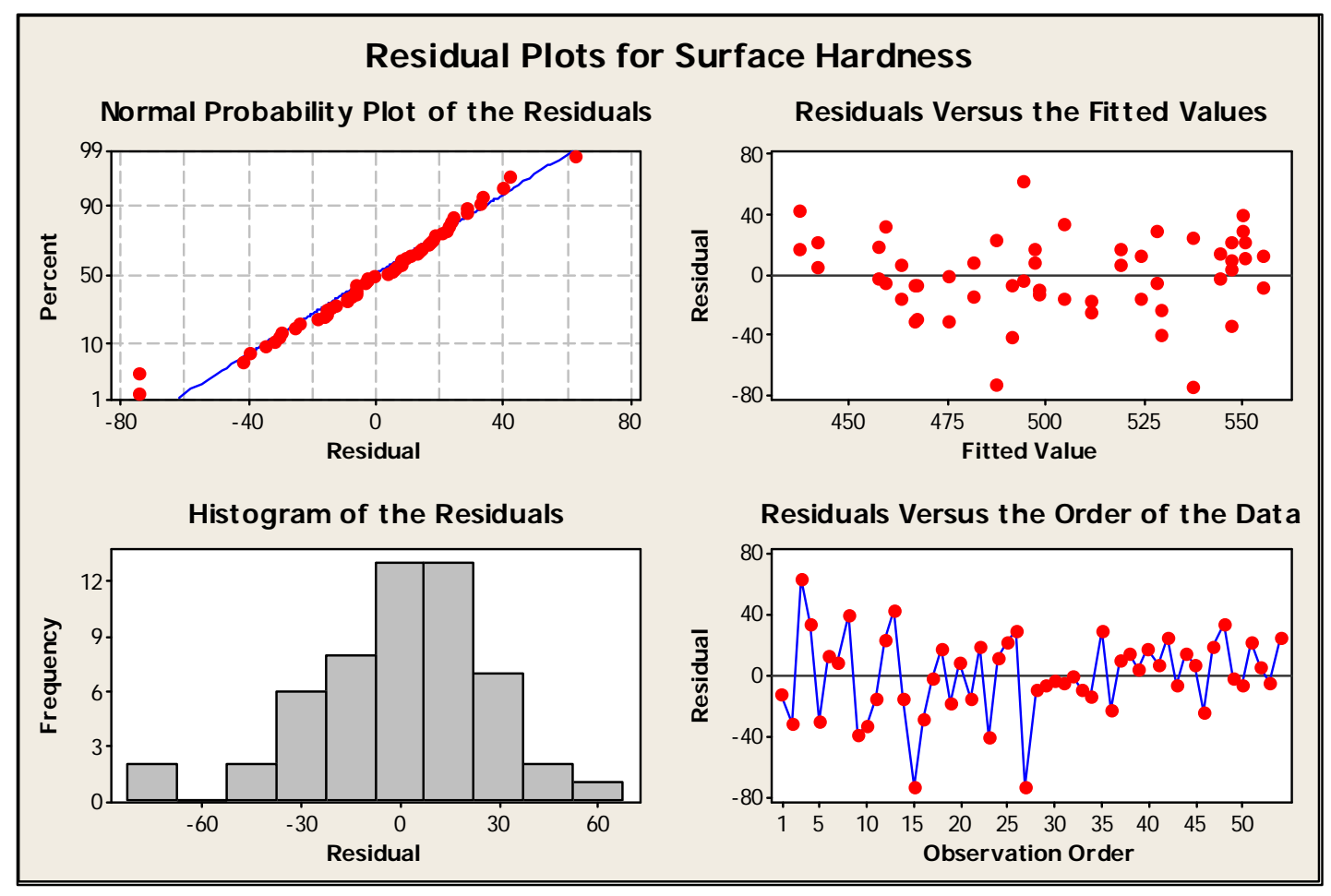

Fig. 1. Residual Plots for Surface Hardness

The ANOVA table revealed that the factors green density $(C)$ \& material $(D)$ and the interaction soaking time $\mathrm{x}$ temperature $(A x B)$ had significant effect surface hardness ( $\mathrm{p}$ value $\leq 0.05$ ). The Fig. 1 showed that the residuals were approximately normally distributed and there was no systematic pattern or trend in the residual versus fitted values or residuals versus order of the data.

The ANOVA table for the response case depth is given in Table 5 and the corresponding residual plots is given in Fig. 2. The Table 5 revealed that the factors soaking time $(A)$, temperature $(B)$ \& green density $(C)$ and the interaction soaking time $x$ temperature $(A x B)$ had significant effect on the response case depth. The figure 2 showed that the residuals were approximately normally distributed and there was no systematic pattern or trend in the residual versus fitted values or residuals versus the order of the data. 
Table 5

ANOVA table for Case Depth

\begin{tabular}{lccccc}
\hline Source & DF & SS & MS & F & p \\
\hline Soaking Time & 2 & 0.59009 & 0.295 & 215.74 & 0.000 \\
Temperature & 2 & 0.126759 & 0.06338 & 46.34 & 0.000 \\
Green Density & 2 & 0.30287 & 0.1514 & 110.73 & 0.000 \\
Material & 2 & 0.000093 & 0.000046 & 0.03 & 0.967 \\
Soaking Time x Temperature & 4 & 0.0788 & 0.0197 & 14.4 & 0.000 \\
Soaking Time x Green Density & 4 & 0.001019 & 0 & 0.19 & 0.944 \\
Error & 37 & 0.050602 & 0.001368 & & \\
\hline Total & 53 & 1.150231 & & & \\
\hline
\end{tabular}

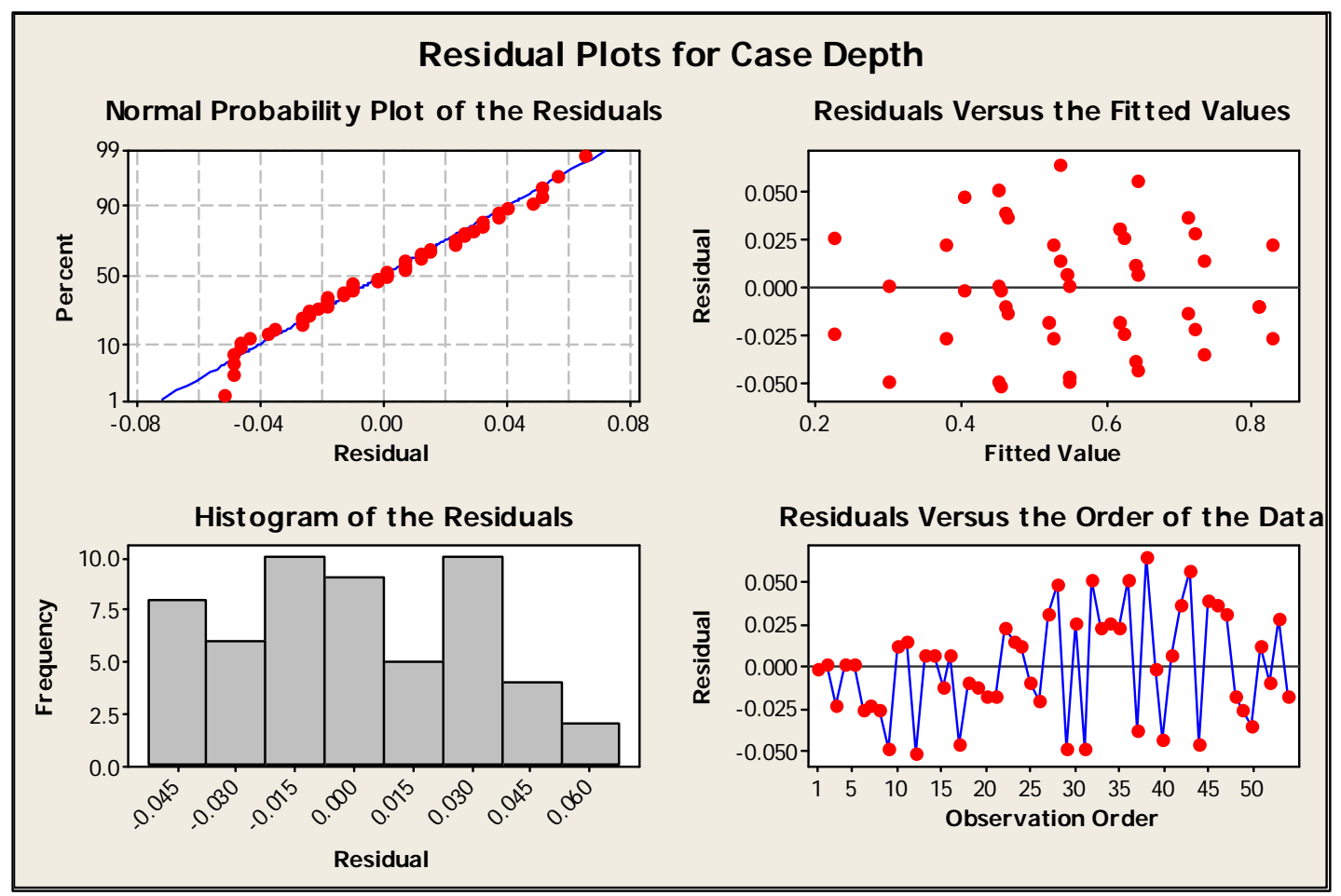

Fig. 2. Residual plots for Case Depth

After identifying the significant factors and interactions, the expected values of the response variables were computed for all the possible 81 combination of factor levels (81 combinations are possible with 4 factors each having 3 levels). The expected response for all these combination can be estimated as the sum of overall mean and the contributing effects of significant factors and interactions (Peace, 1993).

These expected values were then converted into desirability values using Eq. (1). The value of $\alpha$ and $\beta$ were varied from 0.1 to 1.0 and it was found that at 0.1 , the total desirability was highest for the optimum combination. So $\alpha$ and $\beta$ were chosen as 0.1 . Finally the total desirability for each of the 81 combinations was calculated using Eq. (4). The results obtained are given in Table 6. From Table 6, the optimum combination with highest desirability value of 0.9931 was identified as $A_{1} B_{3} C_{3} D_{3}$ (combination 27 in Table 6). The estimated surface hardness and case depth values for the optimum combination were 509.6111 and 0.4463 which were very close to the respective targets of 500 and 0.45 . 
Table 6

Estimated responses for all possible 81 combinations

\begin{tabular}{|c|c|c|c|c|c|c|c|}
\hline SL No & Soaking Time & Temperature & Green Density & Material & Surface Hardness & Case Depth & Desirability \\
\hline 1 & Low & Low & Low & Type I & 495.1667 & 0.213 & 0.9421 \\
\hline $\begin{array}{l}1 \\
2\end{array}$ & Low & Low & Low & Type II & 445.6667 & 0.2102 & 0.8917 \\
\hline 3 & Low & Low & Low & Type III & 444.5 & 0.2102 & 0.8896 \\
\hline 4 & Low & Low & Medium & Type I & 521.7223 & 0.1157 & 0.8429 \\
\hline 5 & Low & Low & Medium & Type II & 472.2222 & 0.113 & 0.8302 \\
\hline 6 & Low & Low & Medium & Type III & 471.0556 & 0.113 & 0.8292 \\
\hline 7 & Low & Low & High & Type I & 542.2778 & 0.0296 & 0 \\
\hline 8 & Low & Low & High & Type II & 492.7778 & 0.0269 & 0 \\
\hline 9 & Low & Low & High & Type III & 491.6111 & 0.0269 & 0 \\
\hline 11 & Low & Medium & Low & Type II & 499 & 0.5352 & 0.9855 \\
\hline 12 & Low & Medium & Low & Type III & 497.8334 & 0.5352 & 0.9848 \\
\hline 13 & Low & Medium & Medium & Type I & 575.0556 & 0.4407 & 0.8689 \\
\hline 14 & Low & Medium & Medium & Type II & 525.5555 & 0.438 & 0.9792 \\
\hline 15 & Low & Medium & Medium & Type III & 524.3889 & 0.438 & 0.9803 \\
\hline 16 & Low & Medium & High & Type I & 595.6111 & 0.3546 & 0 \\
\hline 17 & Low & Medium & High & Type II & 546.1111 & 0.3519 & 0.9423 \\
\hline 18 & Low & Medium & High & Type III & 544.9445 & 0.3519 & 0.9439 \\
\hline 19 & Low & High & Low & Type I & 513.1667 & 0.6324 & 0.9552 \\
\hline 20 & Low & High & Low & Type II & 463.6667 & 0.6296 & 0.9359 \\
\hline 22 & Low & High & Medium & Type I & 539.7223 & 0.5352 & 0.9529 \\
\hline 23 & Low & High & Medium & Type II & 490.2222 & 0.5324 & 0.9803 \\
\hline 24 & Low & High & Medium & Type III & 489.0556 & 0.5324 & 0.9794 \\
\hline 25 & Low & High & High & Type I & 560.2778 & 0.4491 & 0.9323 \\
\hline 26 & Low & High & High & Type II & 510.7778 & 0.4463 & 0.9923 \\
\hline 27 & Low & High & High & Type III & 509.6111 & 0.4463 & 0.9931 \\
\hline 28 & Medium & Low & Low & Type I & 505.3334 & 0.4769 & 0.9926 \\
\hline 29 & Medium & Low & Low & Type II & 455.8333 & 0.4741 & 0.9572 \\
\hline 30 & Medium & Low & Low & Type III & 454.6667 & 0.4741 & 0.9556 \\
\hline 31 & Medium & Low & Medium & Type I & 531.8889 & 0.3796 & 0.964 \\
\hline 32 & Medium & Low & Medium & Type II & 482.3889 & 0.3769 & 0.9761 \\
\hline 33 & Medium & Low & Medium & Type III & 481.2222 & 0.3769 & 0.9752 \\
\hline 34 & Medium & Low & High & Type I & 552.4445 & 0.2935 & 0.9204 \\
\hline 35 & Medium & Low & High & Type II & 502.9444 & 0.2907 & 0.9683 \\
\hline 36 & Medium & Low & High & Type III & 501.7778 & 0.2907 & 0.969 \\
\hline 37 & Medium & Medium & Low & Type I & 488.1667 & 0.6602 & 0.9475 \\
\hline 38 & Medium & Medium & Low & Type II & 438.6667 & 0.6574 & 0.889 \\
\hline 39 & Medium & Medium & Low & Type III & 437.5 & 0.6574 & 0.8861 \\
\hline 40 & Medium & Medium & Medium & Type I & 514.7223 & 0.563 & 0.9708 \\
\hline 44 & Medium & Medium & High & Type II & 485.7778 & 0.4741 & 0.9867 \\
\hline 45 & Medium & Medium & High & Type III & 484.6111 & 0.4741 & 0.9859 \\
\hline 46 & Medium & High & Low & Type I & 508.6667 & 0.863 & 0 \\
\hline 47 & Medium & High & Low & Type II & 459.1667 & 0.8602 & 0 \\
\hline 48 & Medium & High & Low & Type III & 458 & 0.8602 & 0 \\
\hline 49 & Medium & High & Medium & Type I & 535.2223 & 0.7657 & 0.8648 \\
\hline 50 & Medium & High & Medium & Type II & 485.7222 & 0.763 & 0.885 \\
\hline 51 & Medium & High & Medium & Type III & 484.5556 & 0.763 & 0.8842 \\
\hline 52 & Medium & High & High & Type I & 555.7778 & 0.6796 & 0.8931 \\
\hline 53 & Medium & High & High & Type II & 506.2778 & 0.6769 & 0.9452 \\
\hline 54 & Medium & High & High & Type III & 505.1111 & 0.6769 & 0.946 \\
\hline 55 & High & Low & Low & Type I & 529.3334 & 0.6935 & 0.921 \\
\hline 56 & High & Low & Low & Type II & 479.8333 & 0.6907 & 0.9298 \\
\hline 57 & High & Low & Low & Type III & 478.6667 & 0.6907 & 0.9289 \\
\hline 58 & High & Low & Medium & Type I & 555.8889 & 0.5963 & 0.9166 \\
\hline 59 & High & Low & Medium & Type II & 506.3889 & 0.5935 & 0.9699 \\
\hline 60 & High & Low & Medium & Type III & 505.2222 & 0.5935 & 0.9707 \\
\hline 61 & High & Low & High & Type I & 576.4445 & 0.5102 & 0.8478 \\
\hline 62 & High & Low & High & Type II & 526.9445 & 0.5074 & 0.9709 \\
\hline 63 & High & Low & High & Type III & 525.7778 & 0.5074 & 0.972 \\
\hline 64 & High & Medium & Low & Type I & 519.1667 & 0.8019 & 0 \\
\hline 65 & High & Medium & Low & Type II & 469.6667 & 0.7991 & 0.7257 \\
\hline 66 & High & Medium & Low & Type III & 468.5 & 0.7991 & 0.7249 \\
\hline 67 & High & Medium & Medium & Type I & 545.7223 & 0.7046 & 0.8982 \\
\hline 68 & High & Medium & Medium & Type II & 496.2222 & 0.7019 & 0.9361 \\
\hline 69 & High & Medium & Medium & Type III & 495.0556 & 0.7019 & 0.9354 \\
\hline 70 & High & Medium & High & Type I & 566.2778 & 0.6185 & 0.886 \\
\hline 71 & High & Medium & High & Type II & 516.7778 & 0.6157 & 0.9571 \\
\hline 72 & High & Medium & High & Type III & 515.6111 & 0.6157 & 0.958 \\
\hline 73 & High & High & Low & Type I & 494.5 & 0.988 & 0 \\
\hline 74 & High & High & Low & Type II & 445 & 0.9852 & 0 \\
\hline 75 & High & High & Low & Type III & 443.8333 & 0.9852 & 0 \\
\hline 76 & High & High & Medium & Type I & 521.0555 & 0.8907 & 0 \\
\hline 77 & High & High & Medium & Type II & 471.5555 & 0.888 & 0 \\
\hline 78 & High & High & Medium & Type III & 470.3889 & 0.888 & 0 \\
\hline 79 & High & High & High & Type I & 541.6111 & 0.8046 & 0 \\
\hline 80 & High & High & High & Type II & 492.1111 & 0.8019 & 0 \\
\hline 81 & High & High & High & Type III & 490.9444 & 0.8019 & 0 \\
\hline
\end{tabular}


The optimum combination obtained through desirability function method was compared with the best combination obtained through optimising one response at a time. The comparison results are shown in Table 7. The Table 7 showed that optimising surface hardness alone would give a surface hardness almost on target but would result in a case depth of 0.535 much higher than the target value of 0.45 and optimising case depth alone would give a case depth more or less on target but would result in a surface hardness of 560.28 far away from the surface hardness target of 500. Meanwhile the simultaneous optimisation of surface hardness and case depth using desirability function would give a compromise solution of surface hardness equal to 509.61 and case depth equal to 0.4463 reasonably close to the respective targets of 500 and 0.45 . Hence it was decided to implement the optimum combination arrived through desirability function approach.

Table 7

Optimum Combination

\begin{tabular}{llcc}
\hline Response & Optimum Combination & Surface Finish & Case Depth \\
\hline Surface Hardness & $\mathrm{A}_{1} \mathrm{~B}_{2} \mathrm{C}_{1} \mathrm{D}_{2}$ & 499.00 & 0.535 \\
Case Depth & $\mathrm{A}_{1} \mathrm{~B}_{3} \mathrm{C}_{3} \mathrm{D}_{1}$ & 560.28 & 0.4490 \\
Desirability Function & $\mathrm{A}_{1} \mathrm{~B}_{3} \mathrm{C}_{3} \mathrm{D}_{3}$ & 509.61 & 0.4463 \\
\hline
\end{tabular}

\section{Implementation of Solution}

A pilot lot of 12 bushes were carbonitrided with the optimum combination of factors and the response variables surface hardness and case depth were measured. The results obtained were compared with the 95\% confidence interval on expected result. The confidence interval was calculated using the formula (Taguchi et al, 1993)

$100(1-\alpha) \% \mathrm{CI}=\mu_{\exp t} \pm \sqrt{F_{\alpha, 1, v} V_{e}\left(\frac{1}{n_{e}}\right)}$

where $v$ is degrees of freedom of error, $V_{e}$ : mean square (MS) of error and $n_{e}$ : total number of experiments / ( $1+$ sum of degrees of freedom for significant factors and interactions). The data on the pilot implementation of the solution is given in Table 8. The Table 8 showed that the values of response variables were within the confidence interval. Hence it was decided to go ahead with the full-scale implementation of optimum combination.

Table 8

Pilot implementation results

\begin{tabular}{ccc}
\hline SL No & Surface Hardness & Case Depth \\
\hline 1 & 507 & 0.47 \\
2 & 510 & 0.45 \\
3 & 505 & 0.48 \\
4 & 509 & 0.43 \\
5 & 511 & 0.46 \\
6 & 510 & 0.44 \\
7 & 506 & 0.44 \\
8 & 512 & 0.42 \\
9 & 509 & 0.48 \\
10 & 508 & 0.44 \\
11 & 505 & 0.45 \\
12 & 512 & 0.43 \\
\hline $95 \%$ CI & $509.61 \pm 37.21$ & $0.4463 \pm 0.047$ \\
\hline
\end{tabular}


Since the target values of the response variables would vary from customer to customer based on the application of bushes, a program was written in Visual Basic for Application to calculate the total desirability of all the possible 81 factor level combinations and identify the combination with highest desirability with customer specified targets. This helped the management to set the significant factors of carbonitriding process in such a way to produce bushes with customer specified requirements on case depth and surface hardness.

\section{Conclusion}

The paper presented a case study on optimising the heat-treated properties of carbonitrided bushes using design of experiments. Since optimising the response variables individually would adversely impact the performance of other response, the response variables surface hardness and case depth were simultaneously optimised using desirability function. Moreover the study became a useful and effective input to design the production process to manufacture bushes with customer specified heat-treated properties.

\section{References}

Antony, J., Anand, R.B., Kumar, M., \& Tiwari, M. K. (2006). Multiple response optimization using Taguchi methodology and neuro-fuzzy based model. Journal of Manufacturing Technology Management, 17(7), 908-925.

Baragetti, S., \& Terranova, A. (2000). Non-dimensional analysis of shot peening by means of DoE, International Journal of Materials and Product Technology, 15(1/2),131-141.

Bhuiyan, N., Gouw, G., \& Yazdi, D. (2011). Scheduling of a computer integrated manufacturing system: A simulation study. Journal of Industrial Engineering and Management, 4(4), 577-609.

Boby, J. (2012). Optimization of actuator performance using robust engineering and feature selection methodologies: A case study. International Journal of Productivity and Performance Management, 60(6), $642-652$.

Chakravorty, R., Gauri, S.K., \& Chakraborty, S. (2013). Optimization of multiple responses of ultrasonic machine (USM) process: A comparative study. International Journal of Industrial Engineering Computations, 4, 285 - 296.

Dal Re, V. (1999). Use of acoustic emission for defect detection in adhesively bonded cylindrical joints loaded in torsión. International Journal of Materials and Product Technology, 14(5/6), 456 - 466.

Del Castillo, E. and Montgomery, D.C. (1993). A nonlinear programming solution to the dual response problema. Journal of Quality Technology, 25(3), 199 - 204.

Derringer, G. (1994). A balancing act: Optimising product’s properties. Quality Progress, 27(6), 5158.

Harrington, E. (1965). The desirability function. Industrial Quality Control, 21(10), 494 - 498.

Hsu, C.M. (2004). An integrated approach to enhance the optical performance of couplers based on neural networks, desirability functions and tabu search. International Journal of Production Economics, 92(3),241 - 251.

Hung-Chang, Liao. (2004). A data envelopment analysis method for optimising multi-response problems with censored data in the Taguchi method. Computers and Industrial Engineering, 46(4), 817-835.

John, B. (2012). Simultaneous optimization of multiple performance characteristics of carbonitrided pellets: a case study. International Journal of Advanced Manufacturing Technology, 61, 585-594.

Koksoy, O., \& Yalcinoz, T. (2006). Mean square error criteria for multi-response process optimisation by a new genetic algorithm. Applied Mathematics and Computations, 175(2), 1657 - 1674.

Montgomery, D. C. (2001). Design and analysis of experiments, 5th edition. John Wiley \& sons (Asia) Pte. Ltd.

Murali Krishna, P., Ramanaiah, N., \& Prasada Rao, K. (2013). Optimization of process parameters for friction welding of dissimilar aluminium alloys (AA2024-T6 and AA6351-T6) by using Taguchi method. International Journal of Industrial Engineering Computations, 4, 51 - 60. 
Myers, R.H., \& Carter, W.H. Jr. (1973). Response surface techniques for dual response systems. Technometrics, 15(2), 301 - 317.

Peace, G. S. (1993). Taguchi methods: A hands on approach. Addison-Wesley publishing company. USA.

Phadke, M. S. (1989). Quality Engineering using Robust Design. Prentice Hall, USA.

Saha, A., \& Mandal, N.K. (2013), Optimization of machining parameters of turning operations based on multi performance criteria. International Journal of Industrial Engineering Computations, 4, 5160.

Su, C.T., \& Tong, L.I. (1997). Multi-response robust design by principal component analysis. Total Quality Management, 8(6), 409 - 416.

Surm, H., Kessler, O., Hoffmann, F., \& Mayr, P. (2005). Effect of machining and heating parameters on distortion of AISI 52100 steel bearing rings. International Journal of Materials and Product Technology, 24(1/2/3/4), $270-281$

Taguchi, G., Yokoyama, Y., \& Wu, Y. (1993). Taguchi methods: Design of experiments. Quality engineering series volume 4. Japanese standard association.

Wang, X.Y., Wang, J., Xu, W.J., Wu, D.J. and Lei, M.K. (2008). A study of laser surface modification for GCr15 steel. International Journal of Materials and Product Technology, 31(1), 88 -96. 